\title{
OPEN Counterfactual time series analysis of short-term change in air pollution following the COVID-19 state of emergency in the United States
}

Tanujit Dey ${ }^{1,6}$, Pooja Tyagi ${ }^{2,6}$, M. Benjamin Sabath ${ }^{2,3}$, Leila Kamareddine ${ }^{2}$, Lucas Henneman ${ }^{4}$, Danielle Braun ${ }^{2,5}$ \& Francesca Dominici ${ }^{2 凶}$

Lockdown measures implemented in response to the COVID-19 pandemic produced sudden behavioral changes. We implement counterfactual time series analysis based on seasonal autoregressive integrated moving average models (SARIMA), to examine the extent of air pollution reduction attained following state-level emergency declarations. We also investigate whether these reductions occurred everywhere in the US, and the local factors (geography, population density, and sources of emission) that drove them. Following state-level emergency declarations, we found evidence of a statistically significant decrease in nitrogen dioxide $\left(\mathrm{NO}_{2}\right)$ levels in 34 of the 36 states and in fine particulate matter $\left(\mathrm{PM}_{2.5}\right)$ levels in 16 of the 48 states that were investigated. The lockdown produced a decrease of up to $3.4 \mu \mathrm{g} / \mathrm{m}^{3}$ in $\mathrm{PM}_{2.5}$ (observed in California) with range $(-2.3,3.4)$ and up to $11.6 \mathrm{ppb}$ in $\mathrm{NO}_{2}$ (observed in Nevada) with range $(-0.6,11.6)$. The state of emergency was declared at different dates for different states, therefore the period "before" the state of emergency in our analysis ranged from 8 to 10 weeks and the corresponding "after" period ranged from 8 to 6 weeks. These changes in $\mathrm{PM}_{2.5}$ and $\mathrm{NO}_{2}$ represent a substantial fraction of the annual mean National Ambient Air Quality Standards (NAAQS) of $12 \mu \mathrm{g} / \mathrm{m}^{3}$ and $53 \mathrm{ppb}$, respectively. As expected, we also found evidence that states with a higher percentage of mobile source emissions (obtained from 2014) experienced a greater decline in $\mathrm{NO}_{2}$ levels after the lockdown. Although the socioeconomic restrictions are not sustainable, our results provide a benchmark to estimate the extent of achievable air pollution reductions. Identification of factors contributing to pollutant reduction can help guide state-level policies to sustainably reduce air pollution.

There is consistent evidence that short- and long-term exposure to fine particulate matter $\left(\mathrm{PM}_{2.5}\right)$ and nitrogen dioxide $\left(\mathrm{NO}_{2}\right)$ increases the risk of mortality, hospitalization, and other adverse health outcomes ${ }^{1-6,11,12}$. Furthermore, several studies have provided preliminary evidence that short and long-term air pollution exposure increases the risk of hospitalization and death among individuals with COVID-19 ${ }^{4-10}$.

The United States mitigates air pollution through a combination of federal, state, and local air pollution regulations ${ }^{13}$. For example, the federal government sets emissions standards and the NAAQS. They also require states to prepare State Implementation Plans (SIPs) that detail emissions reductions strategies for areas that are not in compliance with the NAAQS (non-attainment areas). SIPs use air quality models to demonstrate how regulating local emissions sources helps a non-attainment area meet the NAAQS. Geographically heterogeneous

${ }^{1}$ Center for Surgery and Public Health, Department of Surgery, Brigham and Women's Hospital, Harvard Medical School, Boston, USA. '2Department of Biostatistics, Harvard T.H. Chan School of Public Health, 677 Huntington Ave, Boston, MA 02115, USA. ${ }^{3}$ Faculty of Arts and Sciences, Research Computing, Harvard University, 38 Oxford Street, Cambridge, MA 02138, USA. 'Department of Civil, Environmental, and Infrastructure Engineering, George Mason University, 4400 University Drive, Fairfax, VA 22030, USA. ${ }^{5}$ Department of Data Science, Dana-Farber Cancer Institute, 450 Brookline Ave, Boston, MA 02215, USA. ${ }^{6}$ These authors contributed equally: Tanujit Dey and Pooja Tyagi. ${ }^{\square}$ email: fdominic@hsph.harvard.edu 
regulations, emission sources, and meteorology, results in varying air pollution concentrations by geographic location $^{13,14}$.

Several studies have examined the impact of a sudden intervention on changes in air pollution (see ${ }^{15}$ for a review). For example, researchers used interrupted time-series designs to quantify the impact of the 1990 Dublin coal ban ${ }^{16}$ and regression discontinuity to identify the arbitrary spatial impact of the China Huai River Policy ${ }^{17}$. An important feature of these studies is that they investigated abrupt and localized changes across a relatively short time span (Dublin coal ban) and spatial scale (Huai River policy) ${ }^{18}$. Because of the abrupt nature of these interventions, defining a hypothetical experiment in these studies was straightforward.

Similarly, we examined the effect of the abrupt lockdown measures implemented in response to the COVID19 pandemic, which produced sudden and significant changes in how society functions, with decreases in road traffic, air traffic, and economic activity ${ }^{19}$. This provided us with an unprecedented opportunity to implement a quasi-experimental design with a well-defined control condition (no pandemic) to estimate the changes in air pollution because of the implementation of these extreme measures. In a quasi-experimental design, the researcher compares outcomes between a treatment group and a control group, just as in a classical experiment; but treatment status (in our context the COVID-19 related intervention) is determined by politics, an accident, a regulatory action, or some other action beyond the researcher's control (in our context the start of the pandemic). See ${ }^{20}$ for a discussion of strengths and limitations of a quasi-experimental design. Furthermore, the spatial heterogeneity in the extent to which air pollution levels changed because of the lockdown measures allowed us to identify factors contributing to these changes.

A number of recent studies have investigated the effect of the COVID-19 pandemic on the levels of different air pollutants in the US ${ }^{21-34}$, globally ${ }^{35-39}$ and for several cities around the world ${ }^{40-51}$. Table 1 summarizes studies that have estimated changes in air pollution levels by comparing air pollution levels during the COVID-19 pandemic period to historical data both in the US and globally.

Regardless of the emerging literature on this topic, these studies for the most part do not simultaneously account for autocorrelation, time trends and seasonality, and meteorological factors. To our knowledge, none of these studies attempt to identify state-level factors contributing to heterogeneity in the air pollution declines across states for both $\mathrm{PM}_{2.5}$ and $\mathrm{NO}_{2}$.

In this study, we had several scientific objectives that distinguish this paper from existing contributions in the literature. More specifically, we 1) develop and implement state-of-the-art time series approaches for counterfactual forecasting to predict weekly state-levels of $\mathrm{PM}_{2.5}$ and $\mathrm{NO}_{2}$ from January 1, 2020, to April 23, 2020, under the hypothetical scenario that the pandemic did not occur. These models account for measured confounding (e.g. meteorological factors), unmeasured confounding (e.g. seasonal variation and time trends) and residual autocorrelation; 2) properly validate the accuracy of the model fitting and account for the uncertainty in the counterfactual forecasts via bootstrap; 3 ) estimate the weekly state-level deviations and 95\% CI between counterfactual (e.g., absent the pandemic) and observed levels of $\mathrm{PM}_{2.5}$ and $\mathrm{NO}_{2}$ from January 1, 2020 to April 23, $2020 ; 4)$ assess whether the deviations between the counterfactual values and the observed values start to deviate in correspondence to key interventions implemented as a result of the pandemic; 5) assess within each state, changes in both $\mathrm{PM}_{2.5}$ and $\mathrm{NO}_{2}$; and finally 6) investigate which state-level characteristics, including emissions sources, contributed the most to these changes, while adjusting for geography and population density.

\section{Materials and methods}

Data acquisition. We gathered and harmonized data from several databases (Table S1). We obtained historical daily monitor data of $\mathrm{PM}_{2.5}$ and $\mathrm{NO}_{2}$ concentrations for January 1, 2015 to August 31, 2019 from the US EPA Air Quality System ${ }^{52}$. We obtained current levels of these air pollutants for August 31, 2019 to April 23, 2020 from the EPA AirNow application programming interface ${ }^{53}$. We linked historical and current monitor data within each state. These data were available for 48 states for $\mathrm{PM}_{2.5}$ and 36 states for $\mathrm{NO}_{2}$. We obtained daily temperature, humidity, and precipitation data from the University of Idaho's GRIDMET project, which were then aggregated to the state level using Google Earth Engine ${ }^{54}$.

We obtained state-level source emissions totals from the National Emissions Inventory for $2014^{55}$, and gathered information on population density and geographic region classification of the states from the United States Census Bureau ${ }^{56,57}$. Finally, we accessed the COVID-19 US State Policy Database ${ }^{58}$ to extract information regarding the dates of COVID-19 related state interventions, including state-level declaration of emergency, shelter-inplace orders, and non-essential business closures for each state. All the data sources are publicly available, they are summarized in Table S1, and also available on GitHub along with all code necessary to conduct the analysis; https://github.com/NSAPH/USA-COVID-state-level-air-pollution-SARIMA-analysis.

Statistical methods. Counterfactual forecasting of air pollution levels starting January 1, 2020. SARIMA models are autoregressive models often used to forecast time series where future observations are correlated with past observations $s^{59,60}$. They have the advantage of accounting for the time trend, seasonality, confounders (e.g., meteorological variables), and residual autocorrelation. We fitted SARIMA models to historical data using weekly state-level air pollution levels (from January 1, 2015, to December 31,2019) accounting for time trend, seasonality, autocorrelation and also accounting for the effect of weather by including temperature, precipitation, and humidity as covariates in the model.

The basis of the SARIMA model is a linear regression of a response variable $\mathrm{Y}_{\mathrm{t}}$ at time $\mathrm{t}$ against the past values $\left(\mathrm{Y}_{\mathrm{t}-1}, \mathrm{Y}_{\mathrm{t}-2}, \ldots\right)$ of $\mathrm{Y}$ and the past forecast errors $\left(\varepsilon_{\mathrm{t}-1}, \varepsilon_{\mathrm{t}-2}, \ldots\right)$. A detailed example of this analysis for $\mathrm{NO}_{2}$ in California is provided in the supplementary materials, including model validation measures (Figures S1-S5).

We conducted the following analyses separately for $\mathrm{PM}_{2.5}$ and $\mathrm{NO}_{2}$ and for each state. The algorithm of the model construction and prediction is presented below. 


\begin{tabular}{|c|c|c|c|c|c|}
\hline Citation & Geographic locations & $\begin{array}{l}\text { COVID19 related } \\
\text { intervention }\end{array}$ & Confounding adjustment & Statistical approach & Results \\
\hline \multirow{3}{*}{ Berman et al. ${ }^{22}$} & \multirow{3}{*}{$\begin{array}{l}\text { United States (all counties in } \\
\text { the U.S. with both } \mathrm{NO}_{2} \text { and } \\
\mathrm{PM}_{2.5} \text { monitors) }\end{array}$} & \multirow{3}{*}{$\begin{array}{l}\text { Reduced traffic and mandated } \\
\text { business closures between } \\
\text { March 13-April } 21 \text {. March } \\
\text { 13th being when U.S. reported } \\
\text { cases exceeded } 2000 \text { and the } \\
\text { first enacted state-wide social } \\
\text { distancing order }\end{array}$} & \multirow{3}{*}{ None } & \multirow{3}{*}{$\begin{array}{l}\text { Two-sided t-tests paired by } \\
\text { county }(\alpha=0.05)\end{array}$} & $\begin{array}{l}25.5 \% \text { reduction }(4.8 \mathrm{ppb}) \text { in } \\
\mathrm{NO}_{2} \text { was observed during the } \\
\text { COVID- } 19 \text { period }\end{array}$ \\
\hline & & & & & $\begin{array}{l}\mathrm{NO}_{2} \text { decline was statistically } \\
\text { significant regardless of when } \\
\text { mandated business closures } \\
\text { were implemented }\end{array}$ \\
\hline & & & & & $\begin{array}{l}11.3 \% \text { statistically significant } \\
\text { reduction }\left(0.7 \mu \mathrm{g} / \mathrm{m}^{3}\right) \text { of } \mathrm{PM}_{2.5} \\
\text { in counties from states that } \\
\text { instituted early non-essential } \\
\text { business closures }\end{array}$ \\
\hline \multirow{3}{*}{$\begin{array}{l}\text { Gillingham et al. }{ }^{28} \text { (Com- } \\
\text { mentary) }\end{array}$} & \multirow{3}{*}{ United States (785 monitors) } & \multirow{3}{*}{ Shutdowns } & \multirow{3}{*}{ Weather and seasonality } & \multirow{3}{*}{$\begin{array}{l}\text { Global polynomial and a two- } \\
\text { step local regression }\end{array}$} & $\begin{array}{l}\mathrm{PM}_{2.5} \text { concentrations have } \\
\text { decreased by around }-0.5 \mu \mathrm{g} / \\
\mathrm{m}^{3} \text { since the start of the } \\
\text { shutdowns }\end{array}$ \\
\hline & & & & & $\begin{array}{l}\text { Estimated } 11 \% \text { NOx decrease } \\
\text { in daily local emissions }\end{array}$ \\
\hline & & & & & $\begin{array}{l}\text { There is insufficient evidence } \\
\text { to prove that there was a } \\
\text { significant decrease in } \text { PM }_{2.5} \\
\text { concentrations in the U.S }\end{array}$ \\
\hline Goldberg et al. ${ }^{24}$ & 20 cities in North America & $\begin{array}{l}\text { COVID-19 Physical distancing } \\
\text { measures (lockdown) (15 } \\
\text { March to } 30 \text { April post- } \\
\text { covid-19 period) }\end{array}$ & $\begin{array}{l}\text { Solar zenith angle and mete- } \\
\text { orological conditions over } \\
\text { very short time scales }\end{array}$ & Average differences & $\begin{array}{l}\text { Adjusted for seasonality and } \\
\text { meteorology, } \mathrm{NO}_{2} \text { had a } \\
\text { median drop of } 21.6 \% \text { before } \\
\text { and after COVID-19 physical } \\
\text { distancing }\end{array}$ \\
\hline Karaer et al. ${ }^{25}$ & Florida & $\begin{array}{l}\text { COVID-19 social distancing } \\
\text { behaviors (March 2020) }\end{array}$ & $\begin{array}{l}\text { Population density and } \\
\text { income }\end{array}$ & $\begin{array}{l}\text { A cross-correlation based } \\
\text { dependency analysis }\end{array}$ & $\begin{array}{l}\text { The decrease in } \mathrm{NO}_{2} \text { concen- } \\
\text { trations and vehicle miles trav- } \\
\text { elled (VMT) started } 2 \text { weeks } \\
\text { before the official stay-at-home } \\
\text { order and resulted in } 54.07 \% \\
\text { and } 59.68 \% \text { decrease in } \mathrm{NO}_{2} \\
\text { and VMT by the end of the } \\
\text { month, respectively }\end{array}$ \\
\hline \multirow[b]{2}{*}{ Miech et al. ${ }^{27}$} & \multirow[b]{2}{*}{ Phoenix } & \multirow{2}{*}{$\begin{array}{l}\text { COVID-19 Stay at home } \\
\text { orders (pre-COVID-19: Jan } \\
\text { 6-March 6 \& Post-COVID-19: } \\
\text { March 13-April 8) }\end{array}$} & \multirow{2}{*}{$\begin{array}{l}\text { Meteorological parameters } \\
\text { (horizontal wind speed, } \\
\text { temperature, precipitation, } \\
\text { and planetary boundary layer } \\
\text { height) }\end{array}$} & \multirow[b]{2}{*}{ Linear regression model } & $\begin{array}{l}\text { No uniform decrease was } \\
\text { found in } \mathrm{CO} \text { or } \mathrm{NO}_{2} \text { across the } \\
\text { three sites studied }\end{array}$ \\
\hline & & & & & $\begin{array}{l}\text { There was a significant } \\
\text { decrease }(45 \%) \text { in } \mathrm{PM}_{10} \text { at all } \\
\text { the sites compared to the past } \\
\text { two years }\end{array}$ \\
\hline \multirow{2}{*}{ Parker et al. ${ }^{26}$} & \multirow{2}{*}{ Southern California } & \multirow{2}{*}{$\begin{array}{l}\text { Stay-At-Home orders (19 } \\
\text { March-30 June of the last } \\
5 \text { years) }\end{array}$} & \multirow{2}{*}{ Meteorological differences } & \multirow{2}{*}{ Average differences } & $\begin{array}{l}\text { Concentrations of } \mathrm{PM}_{2.5} \text { and } \\
\mathrm{NO}_{\mathrm{x}} \text { showed an overall reduc- } \\
\text { tion (10-45\% and } 13-40 \%, \\
\text { respectively) across the basin } \\
\text { in } 2020\end{array}$ \\
\hline & & & & & $\begin{array}{l}\mathrm{O}_{3} \text { concentrations decreased } \\
(9 \mathrm{ppb} \text { or } 22 \%) \text { in the western } \\
\text { part of the basin and increased } \\
(8 \text { ppb or } 15 \%) \text { in the down- } \\
\text { wind areas }\end{array}$ \\
\hline \multirow{3}{*}{ Venter et al. ${ }^{36}$} & \multirow{3}{*}{34 countries } & \multirow{3}{*}{ Lockdown (Jan 1- May 15) } & \multirow{3}{*}{ Meteorological variability } & \multirow{3}{*}{ Linear regression models } & $\begin{array}{l}11 \mu \mathrm{g} / \mathrm{m}^{3} \text { reduction in } \mathrm{NO}_{2} \text { (on } \\
\text { average } 60 \% \text { reduction) }\end{array}$ \\
\hline & & & & & $\begin{array}{l}12 \mu \mathrm{g} / \mathrm{m}^{3} \text { reduction in } \mathrm{PM}_{2.5} \\
\text { (on average } 31 \% \text { reduction) }\end{array}$ \\
\hline & & & & & $\begin{array}{l}4 \mu \mathrm{g} / \mathrm{m} 3 \mathrm{a} \text { increase in } \mathrm{O}_{3}(4 \% \\
\text { increase })\end{array}$ \\
\hline \multirow[b]{2}{*}{ Fu et al. ${ }^{35}$} & \multirow{2}{*}{$\begin{array}{l}20 \text { selected major cities around } \\
\text { the world }\end{array}$} & \multirow{2}{*}{$\begin{array}{l}\text { Lockdown (lockdown period } \\
\text { in each city compared to same } \\
\text { period in the past } 3 \text { years) }\end{array}$} & \multirow[b]{2}{*}{ Meteorological variability } & \multirow{2}{*}{$\begin{array}{l}\text { ANOVA and Tukey's HSD } \\
\text { tests }\end{array}$} & $\begin{array}{l}\mathrm{NO}_{2} \text { decreased significantly } \\
\text { in all cities relative to the past } \\
3 \text { years }\end{array}$ \\
\hline & & & & & $\begin{array}{l}\mathrm{PM}_{2.5} \text { decreased in all cities and } \\
\text { found a significant decrease } \\
\text { in } 9 \text { cities relative to each of } \\
\text { the } 3 \text { years }\end{array}$ \\
\hline Benchrif et al. ${ }^{50}$ & $\begin{array}{l}21 \text { selected cities around the } \\
\text { world }\end{array}$ & Lockdown & None & Descriptive statistics & $\begin{array}{l}\text { PM25 and NO2 concentrations } \\
\text { declined considerably in dif- } \\
\text { ferent cities during lockdown } \\
\text { period }\end{array}$ \\
\hline Hammer et al. ${ }^{51}$ & $\begin{array}{l}\text { China, Europe, and North } \\
\text { America }\end{array}$ & Lockdown (Jan - Apr 2020) & None & $\begin{array}{l}\text { Descriptive statistics and } \\
\text { simulation study }\end{array}$ & $\begin{array}{l}\mathrm{PM}_{2.5} \text { concentrations decreased } \\
\text { in all study locations compared } \\
\text { to same period during } 2018 \\
\text { and } 2019\end{array}$ \\
\hline
\end{tabular}

Table 1. Summary of published studies examining changes in air pollution attributable to COVID-19 related interventions in the US and globally. 
1. We created 1,000 time series bootstraps using Box-Cox and Loess-based decomposition ${ }^{61}$ to separate the time series into the trend, seasonal, and remainder part. The remainder is then bootstrapped. We used historical data from January 1, 2015, to December 31, 2019 (see Figure S2 for an example of $\mathrm{NO}_{2}$ in California).

2. For each bootstrapped time series, we:

- Fit SARIMA models ${ }^{59-61}$ adjusting for meteorological factors, namely temperature, precipitation, and humidity (see Figure S3 for an example of $\mathrm{NO}_{2}$ in California).

- From the fitted SARIMA models, we predict air pollution counterfactual levels (absent the pandemic) during a 16-week period from January 01, 2020, to April 23, 2020 (see Figure S4 for an example of $\mathrm{NO}_{2}$ in California).

3. For each state and for each week, we average the predicted air pollution counterfactual levels across all bootstrap replicates. We denote these averages by $C_{i, j}^{\text {pred }}$, where $i=1,2, \ldots, 16$, and $j$ indicates the state (see Figure $\mathrm{S} 4$ for an example of $\mathrm{NO}_{2}$ in California).

4. For each state $\mathrm{j}$ and for each week $\mathrm{i}$, we estimate the weekly differences $\delta_{i, j}=C_{i, j}^{\text {obs }}-C_{i, j}^{\text {pred }}, i=1,2, \ldots, 16$, between the observed values (under pandemic conditions) and the predicted (assuming that the pandemic did not occur) (see Figure $\mathrm{S} 5$ for an example of $\mathrm{NO}_{2}$ in California). The quantification of the statistical uncertainty of these weekly differences using the bootstrap replicates is called "bagged SARIMA" (see Figures S4 and $\mathrm{S} 5$ for an example of $\mathrm{NO}_{2}$ in California).

The data and code for the analysis is available at https://github.com/NSAPH/USA-COVID-state-level-airpollution-SARIMA-analysis.

Model assessment. To assess the overall predictive performance of the SARIMA model, we repeated the same procedure of model building and prediction as described in the algorithm above, this time training the model based on the data from January 1, 2015 to December 31, 2018, and predicting for a 16-week period from January 01, 2019 to April 23, 2019. This allows us to assess model fit and evaluate our modeling approach absent the pandemic. The main goal of implementing this assessment is to find out the model's performance in prediction absent the pandemic and compare its predictive performance using the average prediction error as defined below during the pandemic.

Average prediction error (APE) for state $j$ :

$$
\operatorname{APE} j=1 / 16 \sum_{(i=1)}^{16} \delta_{(i, j)}, \text { where } \delta_{(i, j)}=C_{(i, j)}^{o b s}-C_{(i, j)}^{\text {pred }}
$$

as defined in Step 4 of algorithm above.

We used the R package auto.arima to select model coefficients with the best predictive capability based on bias-corrected Akaike Information Criterion (AIC) $)^{62,63}$ and then used the mean absolute scaled error (MASE) to evaluate the fit of the model ${ }^{64}$.

Estimating air pollution changes attributable to state-level emergency declarations. In step 2 described above, we start the counterfactual forecasting for the period January 01,2020, to April 23, 2020 without any consideration regarding the date of the intervention (such as the declaration of the state emergency). After the forecasting was complete, we then chose the declaration of the state of emergency as the intervention because it most closely visually aligned with the onset of deviations from the forecasted pollutant concentrations. Other interventions, including the timing of non-essential business closures and shelter-in-place orders, were considered visually (see Figures S7 and S8 in the supplementary material, the differences between these interventions are less than two weeks).

We use $\mathrm{T}_{\mathrm{int}, \mathrm{j}}$ to denote the date of the state intervention (declaration of the state of emergency) for each state $j$. For each state and for each of the two pollutants $\left(\mathrm{PM}_{2.5}\right.$ and $\left.\mathrm{NO}_{2}\right)$, we estimated the parameter $\Delta_{j}$ denoting the change in pollutant concentrations following the state intervention compared to before by calculating:

$$
\Delta_{j}=\Delta_{\text {before }, j}-\Delta_{\text {after }, j}
$$

where $\Delta_{\text {before, }}$ is the median of the weekly deviations, $\delta_{i, j}$, (as defined in step 4 above) for the weeks before the date of the declaration of the state emergency $\left(\mathrm{T}_{\mathrm{int}, \mathrm{j}}\right)$ and $\Delta_{a f t e r, j}$ is the median of these weekly deviations, $\delta_{i, j}$, for the weeks after $\mathrm{T}_{\text {int, }}$. Because of the good fit of the SARIMA model to the historical data (Figure S6), and because the counterfactual forecasting is agnostic to the date of the state level emergency (see Figures S4, S5 for an example of $\mathrm{NO}_{2}$ forecasting in California), we argue that negative estimated values of $\Delta_{j}$ indicate that air pollution levels declined because of the state-level emergency. We note that since the state of emergency was declared at different dates for different states, and the total length of the prediction period was 16 weeks in 2020, therefore the period "before" the state of emergency in our analysis ranged from 8 to 10 weeks and the corresponding "after" period ranged from 8 to 6 weeks.

To identify the states with the most pronounced discrepancy between the pattern of change in $\mathrm{PM}_{2.5}$ and $\mathrm{NO}_{2}$, we calculated the ratio $\left(\rho_{\mathrm{j}}\right)$ for each state $j$, defined as:

$$
\rho_{j}=\Delta_{N_{2}, j} / \Delta_{P M_{2.5}, j}
$$

If $\rho_{j}<0$ the two pollutants changed in opposite directions (i.e., one increased while the other decreased), and the larger the magnitude of $\rho_{j}$, the larger the discrepancy between the pollutants' patterns of change. 
Regression modeling to identify state-level factors contributing to heterogeneity in the air pollution across states. In this part of the analysis, our goal is to quantify the associations between the change in pollutant concentrations during the forecasting period January 01,2020 to April 23, 2020 and several sources of pollutants along with a few geographical variables. The estimated $\Delta_{j}$ (as defined in Eq. 2) is the outcome for each state for each of the two pollutants, separately. We have used the following independent variables: the proportion of emissions from fire sources, stationary sources, and mobile sources (obtained from 2014); population density; and region of the state.Note that the NEI reports four sources of emission: fire, mobile, stationary and biogenic; we used only three of these (fire, stationary, and mobile sources) as predictors in the regression model and therefore, their proportions do not sum to 1 . Instead of using a regular multivariable linear regression model, we chose to use a weighted multivariable linear regression (WMLR) model. The reasons behind using this model are: (1) this model can incorporate the covariance matrix of errors which is quite beneficial for the heteroscedastic data, which is a feature of these data sets (2) because of the variability in pollutants concentrations across states, the WMLR are more robust to the outliers than regular regression models. Lastly, based on the pairwise correlation assessments, besides the main effect of the predictors in the models, we also included all two-factor interaction terms of the predictors. This model not only quantifies better associations between the outcome and the covariates; the goodness of fit performances, using the regular $\mathrm{R}^{2}$ and adjusted $\mathrm{R}^{2}$, are better for these models with the interaction terms compared to models without the interaction terms.

\section{Results}

Short-term change in air pollutants following the COVID-19 state of emergency. For most states, the differences between the SARIMA counterfactual predictions (i.e., assuming the pandemic did not occur) and the observed pollutant values were close to zero during the period before the state-level emergency declaration (Figs. 1,2), but there were significant deviations following the intervention lockdown measures.

We found evidence of a statistically significant decrease in $\mathrm{NO}_{2}$ concentrations following the declaration of a state of emergency in 34 of the 36 states that were investigated (Fig. 1 and Tables S2-a, S3). The change in $\mathrm{NO}_{2}$ following the declaration of a state of emergency $\Delta_{j}$ calculated using Eq. 2, ranged from $-0.6 \mathrm{ppb}$ to $11.6 \mathrm{ppb}$ across the states, with an average change of $3.1 \mathrm{ppb}$ and standard deviation $2.4 \mathrm{ppb}$.

We also found evidence of a statistically significant decline in $\mathrm{PM}_{2.5}$ concentrations in 16 of the 48 states that were studied, including New York and other states in the Northeast and West Coast (Figs. 2, 3, Tables S2-b, S4, and Figure S9). The change in $\mathrm{PM}_{2.5}$ following the declaration of a state of emergency ranged from $-2.3 \mu \mathrm{g} / \mathrm{m}^{3}$ to $3.4 \mu \mathrm{g} / \mathrm{m}^{3}$ across the states, with an average change of $0.3 \mu \mathrm{g} / \mathrm{m}^{3}$ and standard deviation $1.3 \mu \mathrm{g} / \mathrm{m}^{3}$.

In Figures S10 and S11 we show the difference between actual and predicted levels of $\mathrm{NO}_{2}$ and $\mathrm{PM}_{2.5}$, respectively for all states. Even though the date of the lockdown was not incorporated into the SARIMA model for counterfactual forecasting, the observed values were closer to the predicted values of $\mathrm{NO}_{2}$ before the state of emergency declarations compared to after the state of emergency declarations. For $\mathrm{PM}_{2.5}$ the differences before and after the state of emergency declarations are not as large.

To quantify how well the SARIMA models can predict for a given period, as described in the Methods section we compared the predictive performances of the models during the same period for 2019 (no pandemic) compared to the main analysis for 2020 (pandemic). We assessed how the APE behaves for both 2019 and 2020 for each state. From Figs. 4 and 5, except for a few states, the APEs are higher for 2020 compared to 2019 for each pollutant model. In addition to using the APE, we also summarize information regarding the model evaluation in the supplementary materials. Figure S3 shows that, for example, the SARIMA model has excellent goodness of fit for the historical data for $\mathrm{NO}_{2}$ in California.

We also found that MASE for the fitted models was less than 1 unit for each pollutant in each state (Figure S6), indicating that the SARIMA model outperformed one-step naïve forecasts, which use the value at time ' $t$ ' to predict the outcome at $t+1$.

Figure 6 shows the estimated $\rho_{\mathrm{j}}$ defined as the ratio of the estimated $\Delta_{j}$ for $\mathrm{NO}_{2}$ divided by the estimated $\Delta_{j}$ for $\mathrm{PM}_{2.5}$. More than one-third of the states (13 states) had $\rho<0$, i.e., these states experienced a decrease in $\mathrm{NO}_{2}$ and a simultaneous increase in $\mathrm{PM}_{2.5}$. The contrast between the pattern of change of $\mathrm{NO}_{2}$ and $\mathrm{PM}_{2.5}$ following state-level emergency declarations suggests that dominating sources of these two pollutants are different in those states. It is also noticeable from Fig. 6 that, for these 13 states the changes in $\mathrm{PM}_{2.5}$ are not statistically significant (Table S2-b) and in 3 states (CO, GA, WA), the $\mathrm{NO}_{2}$ changes are not significant either (Table S2-a). We see more states with statistically significant changes in $\mathrm{NO}_{2}$, than $\mathrm{PM}_{2.5}$, following state-level emergency declarations.

State-level factors may explain the heterogeneity in air pollution declines across states. To ascertain which state-level factors might explain the heterogeneity in the extent to which the air pollution declined across states, we fit a weighted multivariable linear regression model with the estimated $\Delta_{j}$ (for each pollutant separately) for each state as the dependent variable, and geography, population density and sources of emission as predictors accounting for the main effect and their corresponding two-factor interactions. For the $\mathrm{PM}_{2.5}$ pollutant model, all the proportions of annual emissions from a state's stationary (e.g., industrial processes), mobile (e.g., road and air traffic), and fire sources (e.g., agricultural field burning) (Table S5, from 2014) are not statistically significant and have negative associations with the change in $\mathrm{PM}_{2.5}$ concentration (Table S6). In contrast, the proportion of annual emissions from mobile sources and stationary sources were statistically significantly associated with the change in $\mathrm{NO}_{2}$ concentration (Table S6). 
(a)
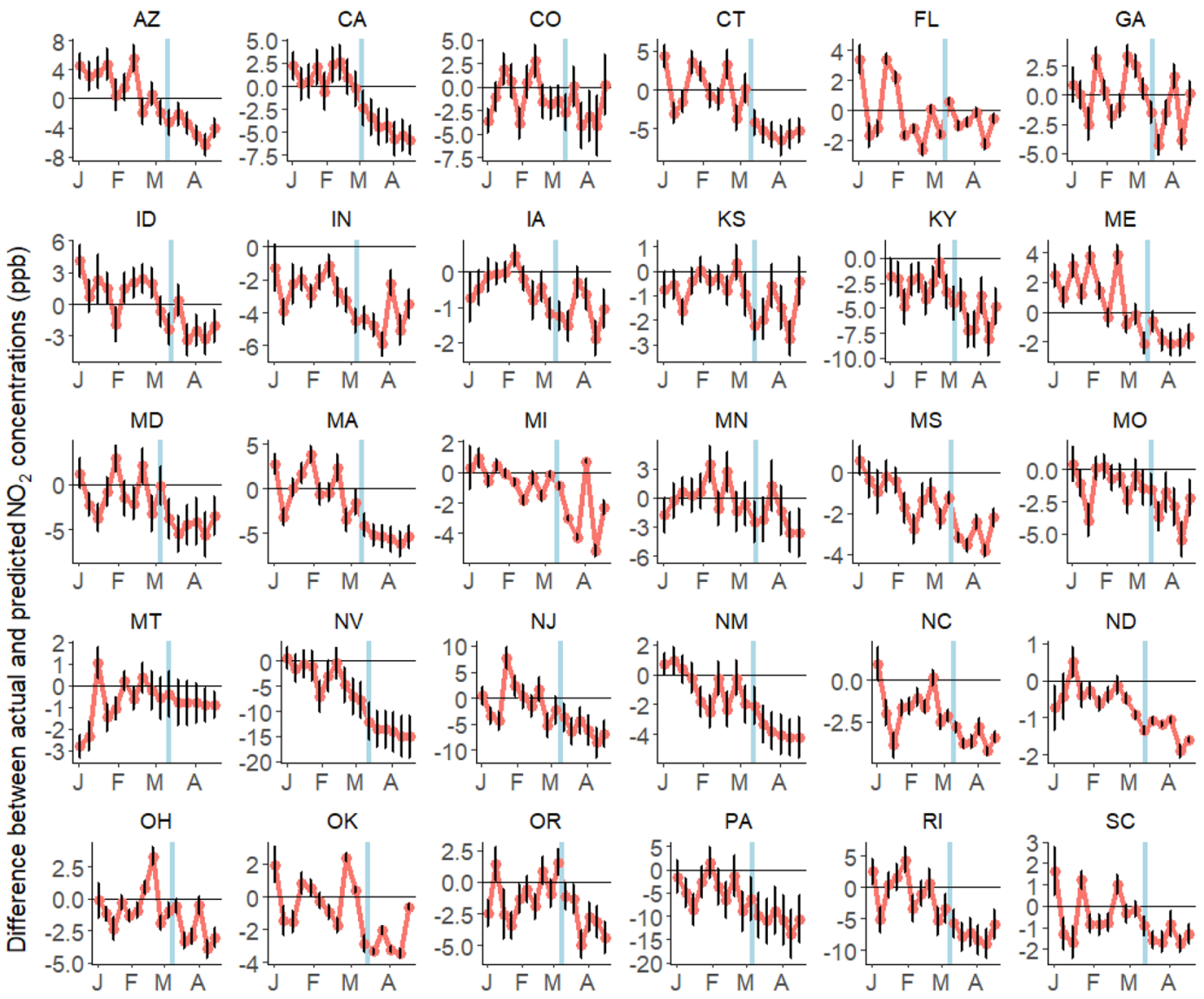

IA

KS

$\mathrm{KY}$

$\mathrm{ME}$
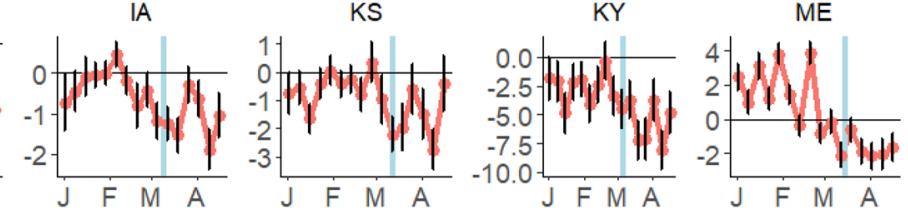

$\mathrm{MN}$

MS

MO
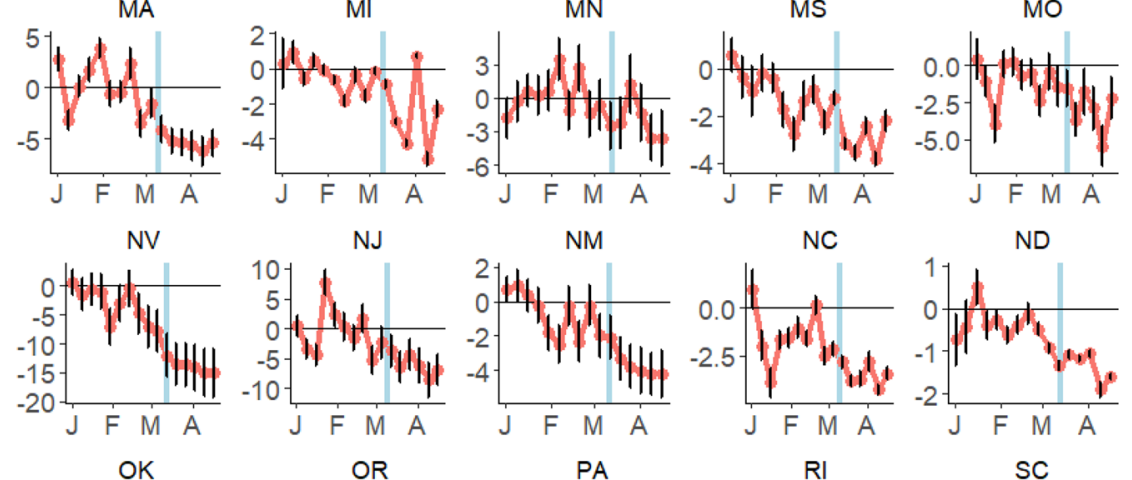

RI
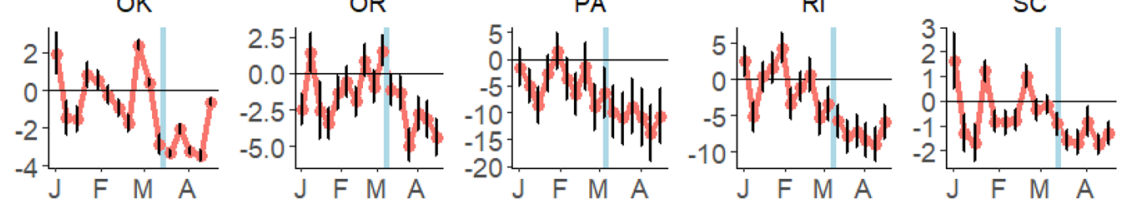

UT

VT
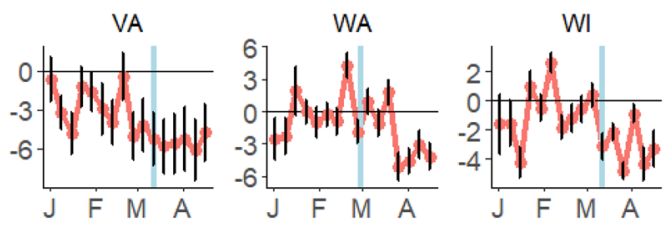

WY

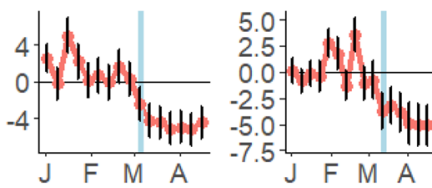

(b)

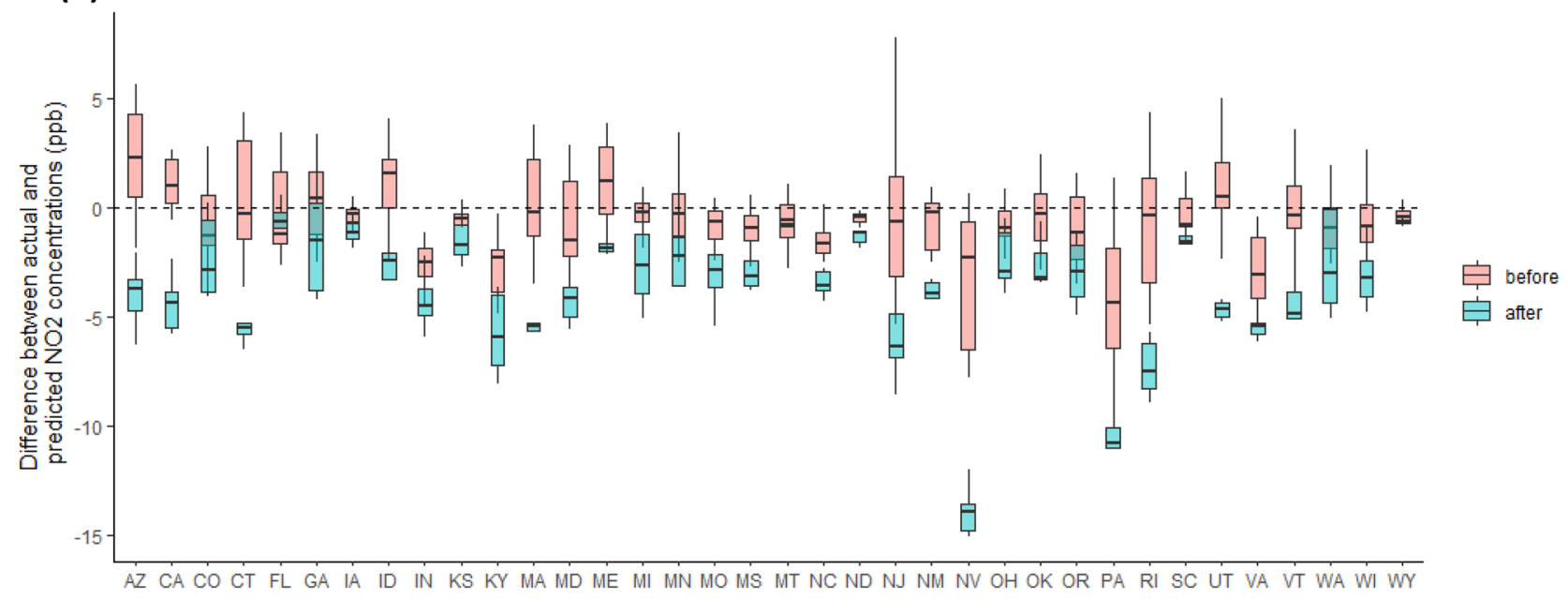

Figure 1. (a) Weekly deviations between observed $\mathrm{NO}_{2}$ concentrations and counterfactual predictions (e.g., absent the pandemic) for each state. The counterfactual predictions were made for 16 weeks from January 1 to April 23, 2020. The blue vertical line marks the date of the declaration of a state of emergency in each state. (b) Boxplots of the weekly deviations for the weeks before (pink) and for the weeks after (blue) the date of the declaration of a state of emergency in each state. 
(a)
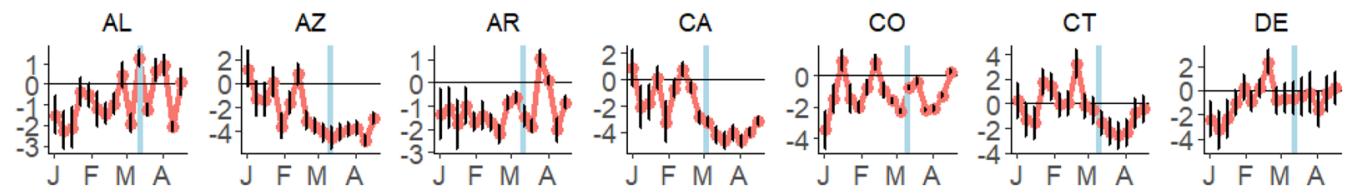

FL

GA

ID

IL

IN

IA

KS
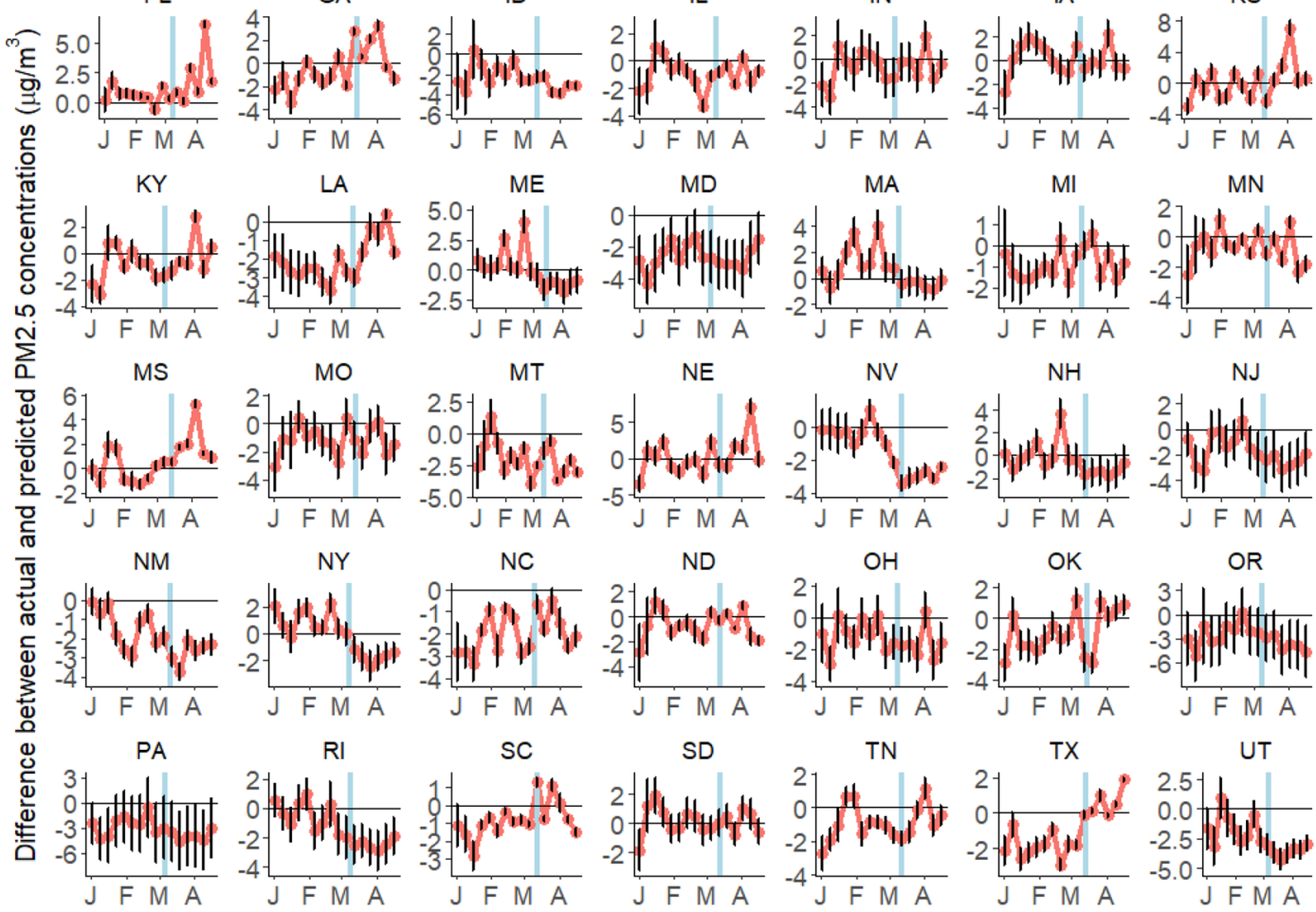

NE

NV

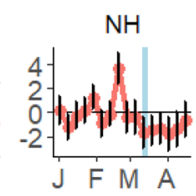

$\mathrm{NJ}$
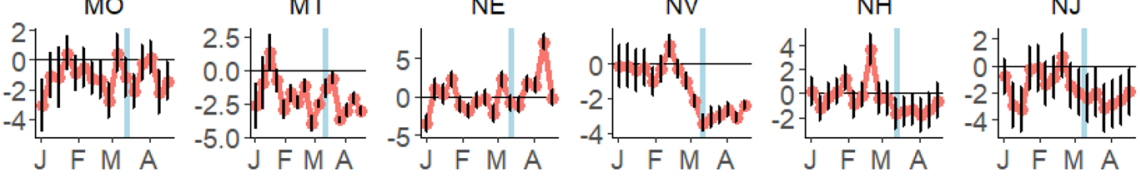

NY

NC

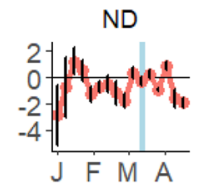

$\mathrm{OH}$

OK

OR
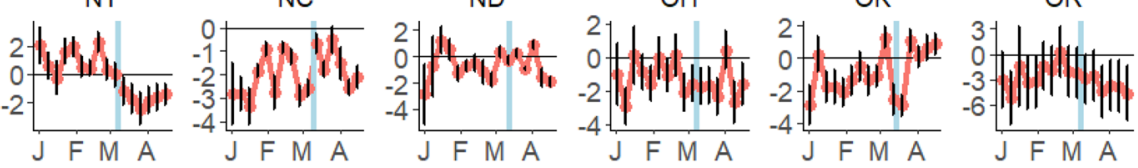

RI SC
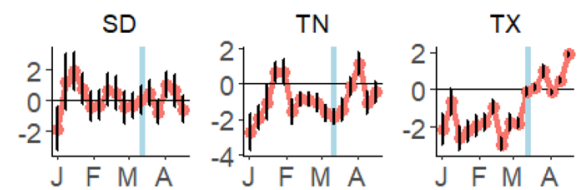

UT
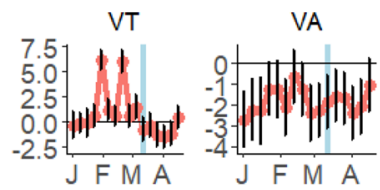

WA

WV

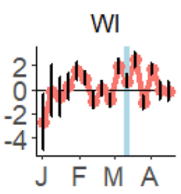

WY
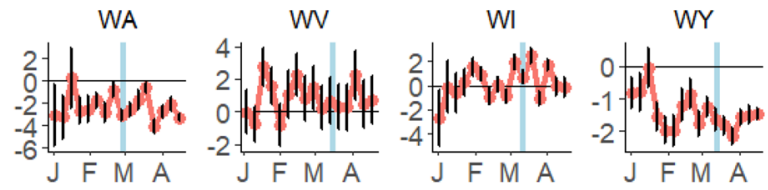

(b)

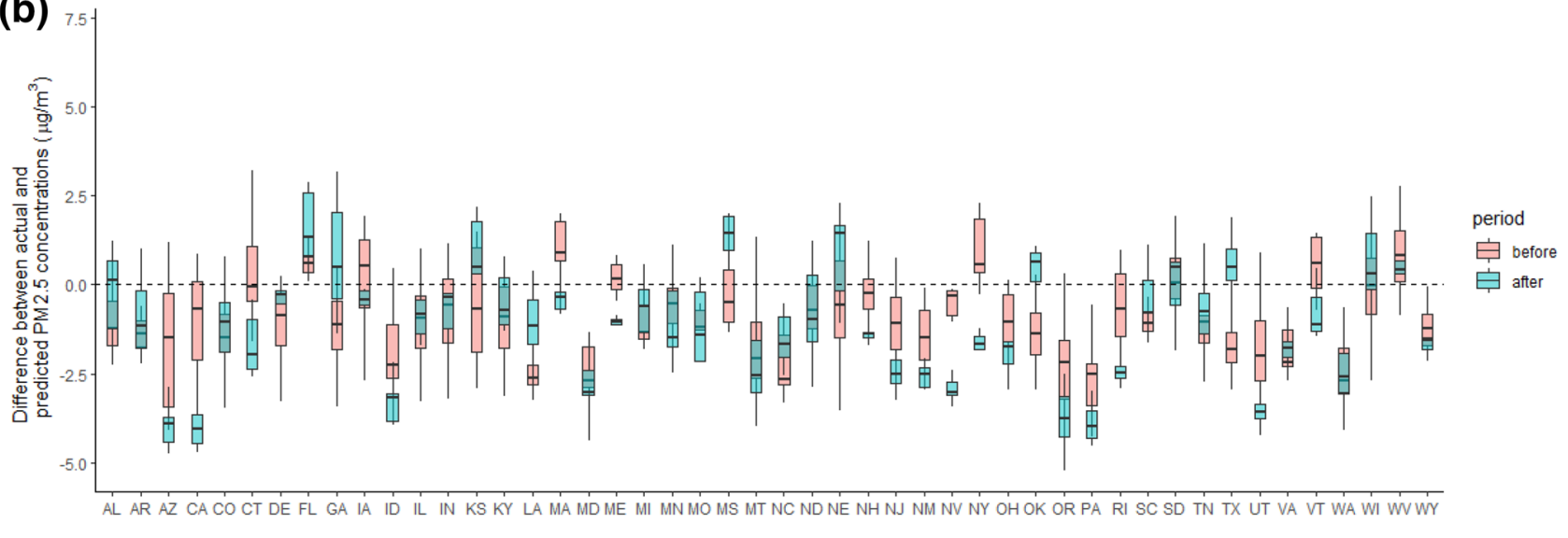

Figure 2. (a) Weekly deviations between observed $\mathrm{PM}_{2.5}$ concentrations and counterfactual predictions (e.g., absent the pandemic) for each state. The predictions were made for 16 weeks from January 1 to April 23, 2020. The blue vertical line marks the date of the declaration of a state of emergency in each state. (b) Boxplots of the weekly deviations for the weeks before (pink) and for the weeks after (blue) the date of the declaration of a state of emergency in each state. 


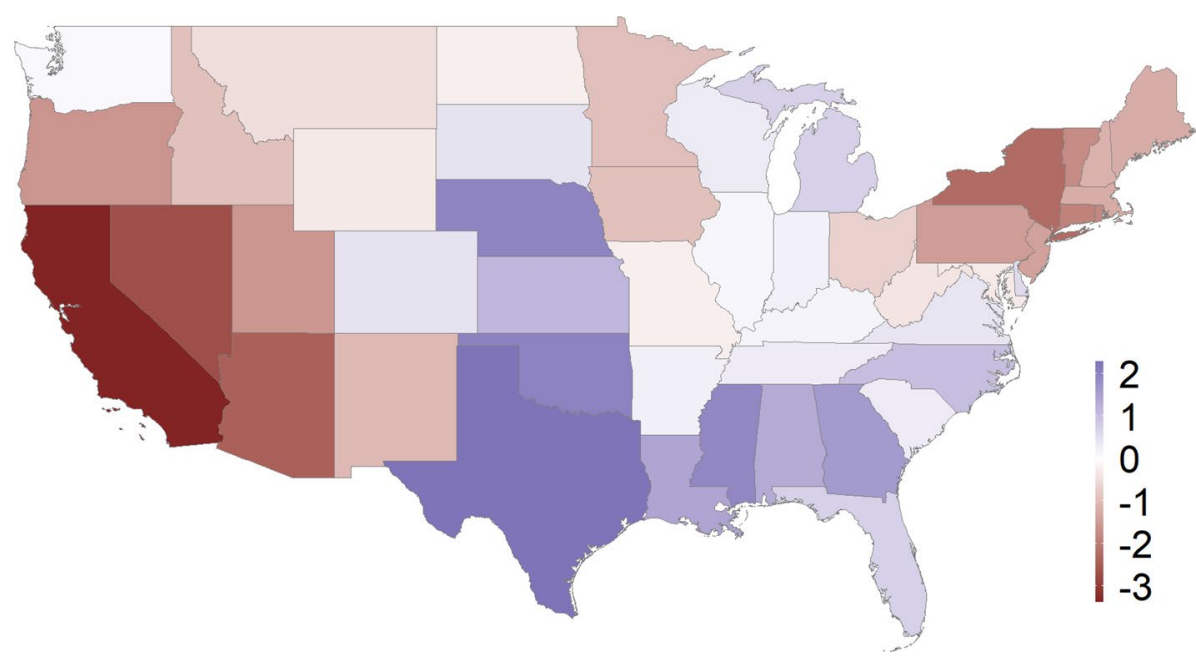

Figure 3. Median change in $\mathrm{PM}_{2.5}$ following the state-level emergency declaration for each state $\left(\Delta_{j}\right) . \mathrm{A}$ negative estimated value of $\Delta_{j}$ indicates that air pollution levels declined as a result of the state-level emergency declaration. This figure was created using open source software R 4.1.0 (https://cran.r-project.org/). The base US map was used by using the R package: rnaturalearthhires (). The source code (Rcode_PM25_USmap_figure3.R) to recreate this figure, please visit our GitHub page: https://github.com/NSAPH/USA-COVID-state-level-airpollution-SARIMA-analysis.

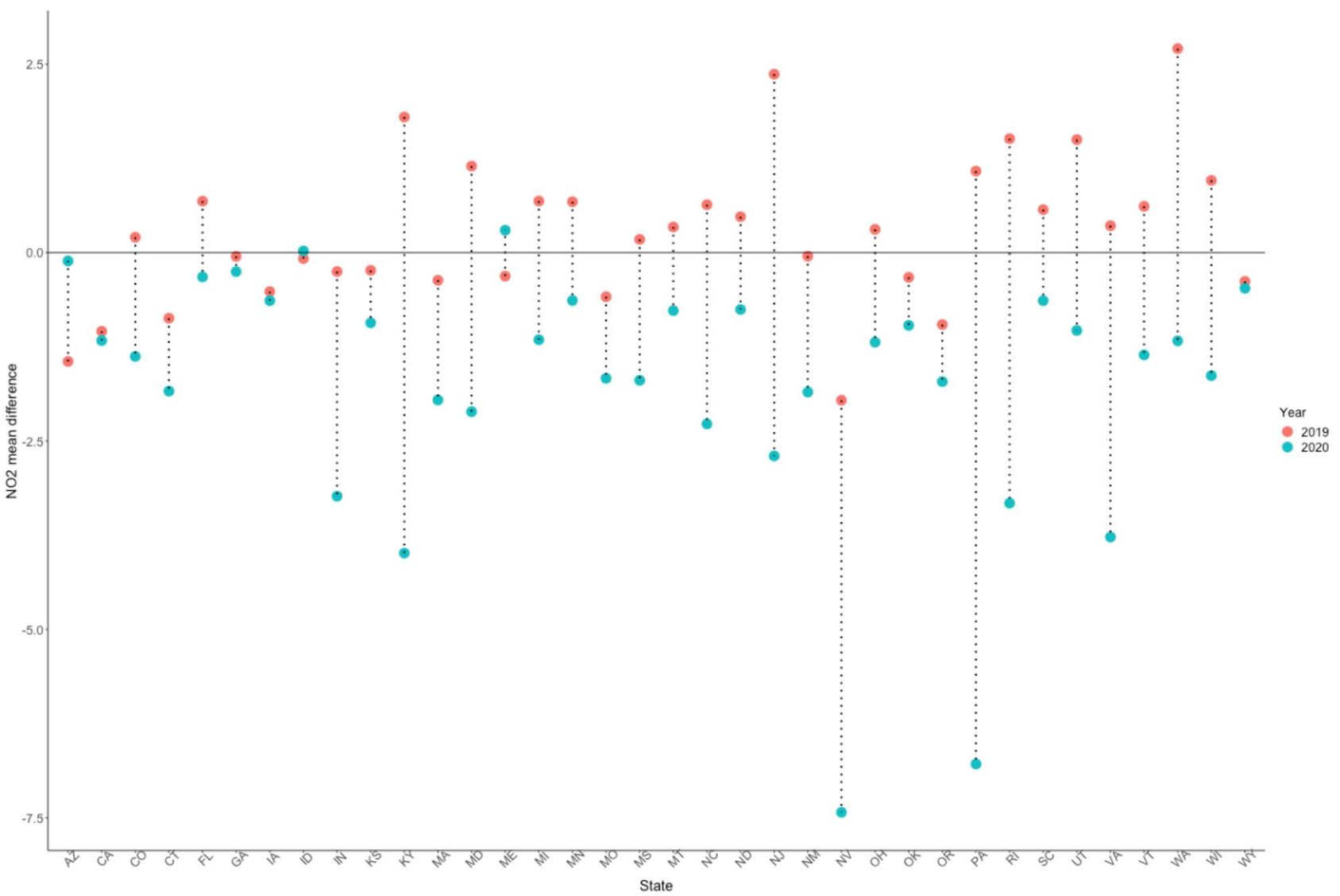

Figure 4. Average prediction error for each state during the same prediction period (January 1 to April 23) for 2019 (no pandemic, red) and 2020 (pandemic, blue) for the $\mathrm{NO}_{2}$ pollutant model (the circles are connected by the dotted line for improved visualization, no other intention is associated in this connection). 


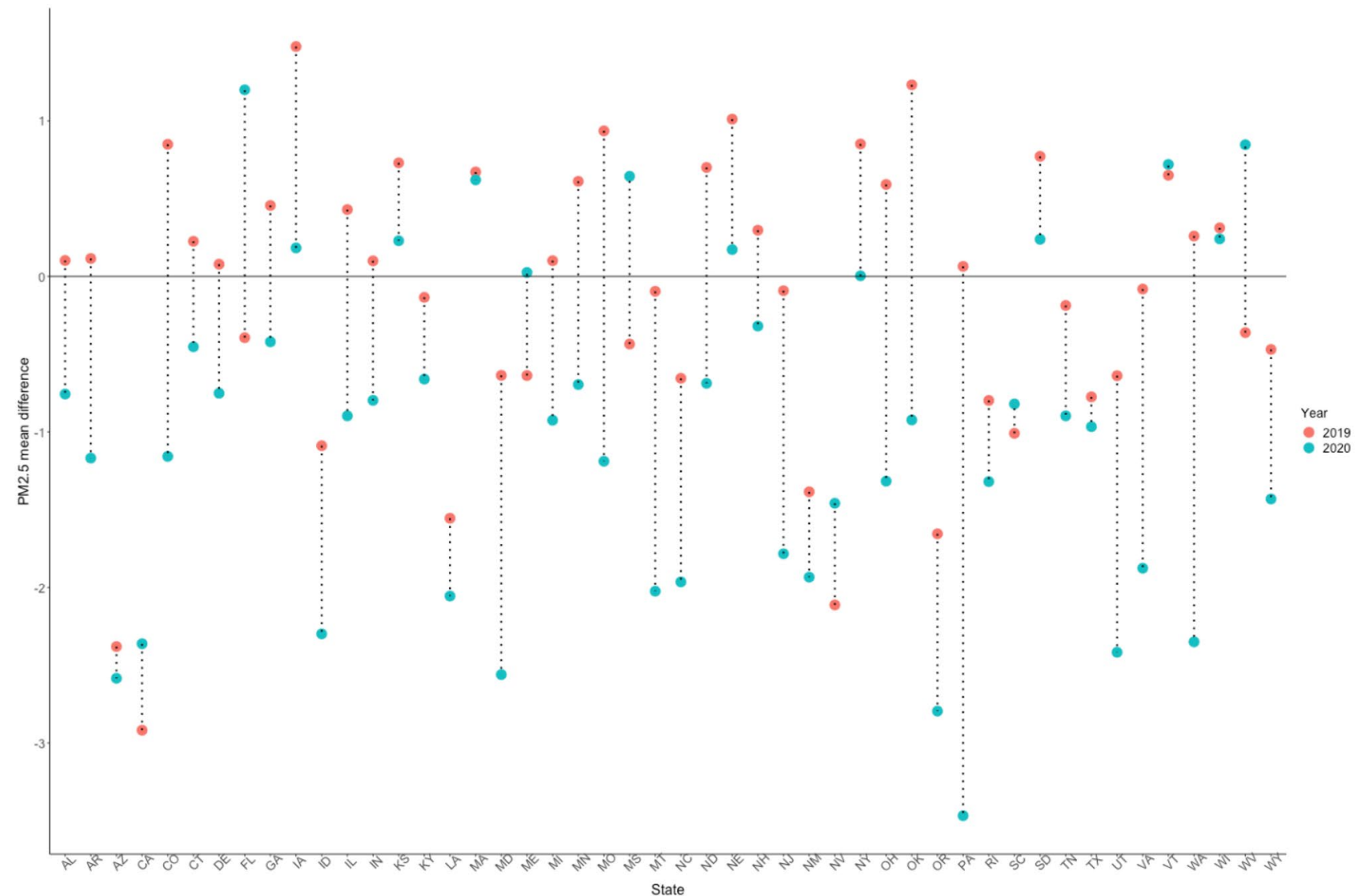

Figure 5. Average prediction error for each state during the same prediction period (January 1 to April 23) for 2019 (no pandemic, red) and 2020 (pandemic, blue), for the $\mathrm{PM}_{2.5}$ prediction model (the circles are connected by the dotted line for improved visualization, no other intention is associated in this connection).

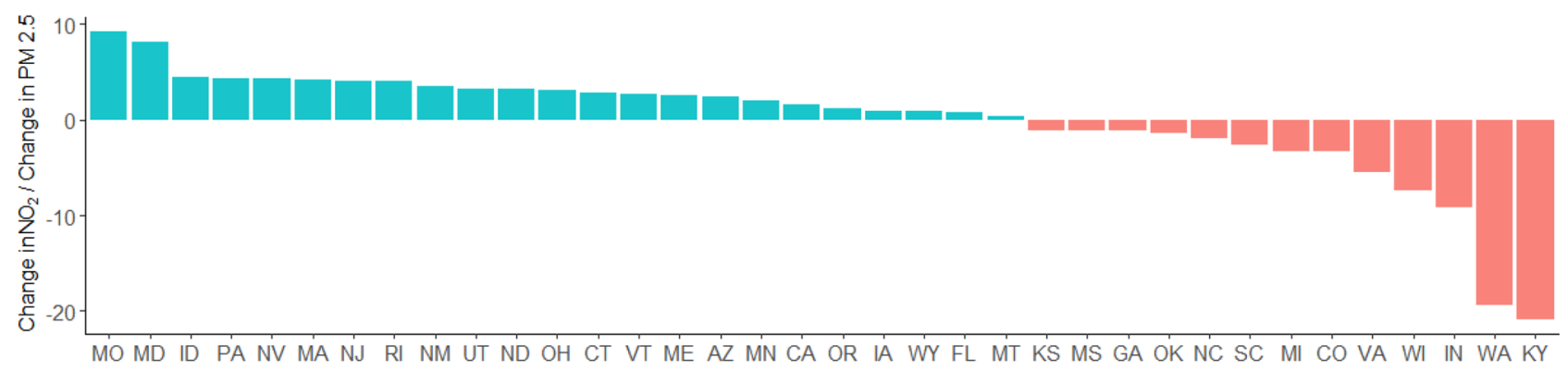

Figure 6. Ratio of the estimated $\Delta_{j}$ for $\mathrm{NO}_{2}$ divided by the estimated $\Delta_{j}$ for $\mathrm{PM}_{2.5}(\rho)$. A negative ratio implies that the change in $\mathrm{NO}_{2}$ following the declaration of the state of emergency was in the opposite direction of the corresponding changes for $\mathrm{PM}_{2.5}$ (i.e., one pollutant increased while the other decreased). For example, in $\mathrm{KY}$, we found a decline in $\mathrm{NO}_{2}$ but an increase in $\mathrm{PM}_{2.5}$ following the state-level emergency declaration.

\section{Discussion}

Following the declaration of a state of emergency, we found that $\mathrm{NO}_{2}$ concentrations showed a statistically significant decline in 34 of the 36 states included in this analysis. In contrast, $\mathrm{PM}_{2.5}$ concentrations declined in only 16 of 48 states included in this analysis. These 16 states are in the Northeast and on the West Coast. Furthermore, as expected, we found that the proportion of a state's annual emissions from mobile sources and stationary sources are statistically significant factors in $\mathrm{NO}_{2}$ changes in response to the state emergency declaration. For $\mathrm{PM}_{2.5}$ reductions, all three sources-mobile, stationary, and fire-were not statistically significant predictors and have negative associations with the changes in $\mathrm{PM}_{2.5}$ concentrations. We concluded that state of emergency declarations implemented in response to the COVID-19 pandemic predominantly affected mobile sources (e.g., cancelled flights and reduced traffic ${ }^{65}$ and stationary sources and led to a decline in $\mathrm{NO}_{2}$. However, because the major sources of $\mathrm{PM}_{2.5}$ are stationary (e.g., industrial fuel combustion), these were less affected by state-level emergency declarations (Table S5). 
SARIMA models have some advantageous features compared to other statistical approaches. Recent studies $^{22,23,29,36}$ have used t-tests ${ }^{22}$, a robust difference approach ${ }^{23}$, linear regression ${ }^{36}$, and synthetic control methods ${ }^{66}$ to study the changes in US air pollution attributable to the COVID-19 shutdown. Bekbulat et al. used temporal correction in their robust differences approach ${ }^{23}$ (not peer-reviewed on August 03, 2020) and Venter et al. included meteorological factors in their regression ${ }^{36}$. The latter was a global study of air pollution changes during the pandemic, which found that a decline in $\mathrm{NO}_{2}$ in the United States occurred on a national level. However, these methods do not directly incorporate the correlations between observed pollutant concentrations, and trends and seasonality in the data. We accounted for both factors using SARIMA models. Any contribution to the data from generally decreasing air pollution trends and weather seasonality must be removed to best estimate the effect of pandemic-related extreme measures on air pollution. By further combining SARIMA with bootstrapping, we were able to quantify the uncertainty in the estimated mean predictions.

We note that our counterfactual predictions of pollutant concentrations assume that the trend and seasonality during the last five years (i.e., the training period for the model) persisted during the prediction period (January 1,2020, to April 23,2020). Another assumption was that the relationship between meteorological variables used in the SARIMA model (temperature, humidity, and precipitation) and the pollutant concentrations were the same in both the training and prediction periods ${ }^{67,68}$. While in California for $\mathrm{NO}_{2}$ (see Figures S1 to S5) we see smaller differences between predicted and observed concentrations before the state of emergency, in some states this was not the case, and we see differences between the predicted and observed for the entire January 2020-April 2020 period. We would not expect the model's predictive capability to affect the estimation of the pollutant concentrations before and after the state intervention differently. Therefore, where we observed significant deviations from the predicted concentrations following the state intervention, we can be confident that it is due to the intervention and not due to the model's predictive capability. Additionally, we fit an additional SARIMA model to predict the same prediction period for the previous year of 2019 (January 1, 2019, to April 23, 2019). In comparing the behaviour of the APEs, we find that APEs are higher for 2020 compared to 2019, except for a few states, for each of the pollutant models.

In contrast to other studies (see for example ${ }^{22}$ ), we did not a priori divide our data into pre- and postCOVID-19 periods. We used January 1, 2015, to December 31, 2019 as historical data and then used the SARIMA model to predict the counterfactual pollutant levels during the 16-week period from January 1, 2020 to April 23, 2020, under the hypothesis that neither the pandemic nor the state emergency declaration occurred. In other words, first we predict air pollution levels for the whole study period of 16 weeks. We then looked a posteriori to determine if the $\mathrm{NO}_{2}$ or $\mathrm{PM}_{2.5}$ declines coincided with state-level emergency declarations (see Figures S1-S5 for example of $\mathrm{NO}_{2}$ in California).

By identifying the maximum decline in the median pollutant concentrations following state-level emergency declaration, we found that the extreme measures taken during the pandemic led to a change of $\mathrm{PM}_{2.5}$ of up to $3.4 \mu \mathrm{g} / \mathrm{m}^{3}$ (in California) and a change of $\mathrm{NO}_{2}$ of up to $11.6 \mathrm{ppb}$ (in Nevada). These weekly-averaged values represent a substantial fraction of the annual mean NAAQS values of $12 \mu \mathrm{g} / \mathrm{m}^{3}$ and $53 \mathrm{ppb}$, respectively. Based on the national regression model, there is significant potential to reduce $\mathrm{NO}_{2}$ concentrations by reducing mobile and stationary sources of $\mathrm{NO}_{2}$ emissions, provided the same level of change can be sustained throughout the annual cycle. But these associations were not seen in the $\mathrm{PM}_{2.5}$ regression model. In Table 1, we summarized the published evidence from similar studies in the US. For example, Berman el al 2020, examines all the counties in the US for both $\mathrm{PM}_{2.5}$ and $\mathrm{NO}_{2}$. They found a $25.5 \%$ reduction (4.8 ppb) in $\mathrm{NO}_{2}$ during the COVID-19 period and a $11.3 \%$ statistically significant reduction $\left(0.7 \mu \mathrm{g} / \mathrm{m}^{3}\right)$ of $\mathrm{PM}_{2.5}$ in counties from states that instituted early non-essential business closures ${ }^{22}$. However, the statistical analysis of this study relies on t-tests and does not account for confounding or residual autocorrelation. Overall, among studies summarized in Table 1, there is consistent evidence of a decline of $\mathrm{NO}_{2}$ for most of the locations ${ }^{22,24-26}$, whereas the evidence of declines in $\mathrm{PM}_{2.5}$ is weaker (see for example 26,28 ). In addition, one relevant pre-print study found that $\mathrm{PM}_{2.5}$ concentrations during lockdown are $10 \%\left(0.54 \mu \mathrm{g} / \mathrm{m}^{3}\right)$ higher than expected post-covid, but $11 \%\left(0.73 \mu \mathrm{g} / \mathrm{m}^{3}\right)$ lower than precovid, with $31 \%$ decrease in $\mathrm{NO}_{2}$ levels in 3 major cities ${ }^{23}$. Another relevant pre-print study found a nationwide average increase of $1.36 \mu \mathrm{g} / \mathrm{m}^{3}$ in $\mathrm{PM}_{2.5}$ following official lockdown orders ${ }^{66}$.

With respect to studies outside the US, a recent study investigated the effect of lockdown in urban China, using difference-in-difference approach; they found a decline of $14 \mu \mathrm{g} / \mathrm{m}^{3}$ in locked-down cities compared to cities that did not implement a lockdown ${ }^{69}$. The cities in that study had baseline $\mathrm{PM}_{2.5}$ concentrations four times higher than the safe limits set by the World Health Organization, which may have been partly responsible for a larger decline after lockdown compared to what we observed in the United States. Another study used baseline regression to estimate the impact of lockdown on 44 cities in Northern China and found a $5.93 \%$ decrease in $\mathrm{PM}_{2.5}$ and a $24.67 \%$ decrease in $\mathrm{NO}_{2}$ concentrations during lockdown ${ }^{40}$. Others have used paired t-tests and the autoregressive moving average (ARMA) model to quantify the impact of the COVID-19 lockdown in 41 cities in India on pollution levels, and found a $19 \%$ decrease in $\mathrm{NO}_{2}$ compared to the same period in $2019^{45}$.

Our study results support the effectiveness of state-level actions to reduce ambient levels of $\mathrm{PM}_{2.5}$ and $\mathrm{NO}_{2}$, and specifically, that restrictions on stationary and mobile sources of air pollution could decrease $\mathrm{NO}_{2}$ emissions even further in states where mobile sources constitute a larger proportion of annual emissions. In contrast, $\mathrm{PM}_{2.5}$ concentration reduction may not be as easily achieved through these sources alone. In states where changes in $\mathrm{PM}_{2.5}$ and $\mathrm{NO}_{2}$ exhibited opposite trends (one increased while the other decreased), lowering the emission of $\mathrm{NO}_{2}$, by decreasing mobile source emissions for example, may not necessarily decrease $\mathrm{PM}_{2.5}$ concentrations.

Study limitations. The models were fit separately for $\mathrm{PM}_{2.5}$ and $\mathrm{NO}_{2}$ and we did not account for correlation between the two pollutants. We relied on state-level concentration averages and the 2014 emissions inventory. While our study would benefit greatly from a more recent emissions inventory (or spatial emissions estimates 
during the interventions), to our knowledge, such data is not currently available publicly. With respect to fire emissions, we note that although we only have data from 2014, regions with higher areas burned in 2014 have larger propensity to have higher areas burned in $2020^{70}$. Trading finer spatial resolution in the monitoring datanot averaging to the state level-may reveal important sub-state variability in lockdown impacts. Monitor data was obtained from EPA AirNow and has not undergone quality control by the EPA. We didn't remove outlier observations, however we averaged hourly measurements by day and by state, which would have minimized the impact of outliers. Our approach also does not consider the spatial correlations between pollutant concentrations, which may help explain concentration changes in non-local pollutants such as $\mathrm{PM}_{2.5}$. Wind speed was not included in the SARIMA model, adjusting for wind speed could have improved the predictions even more. Finally, data were available for 36 states for $\mathrm{NO}_{2}$ and 48 states for $\mathrm{PM}_{2.5}$, which limited the number of observations in the weighted regression model. Finally, even though we have accounted for the interactions between the predictors in the weighted least squares regression models, we need to consider adjusting for other potential predictors which could improve the prediction.

Received: 13 November 2020; Accepted: 19 November 2021

Published online: 07 December 2021

\section{References}

1. Crouse, D. L. et al. Ambient $\mathrm{PM}_{2.5}, \mathrm{O} 3$, and NO 2 Exposures and Associations with Mortality over 16 Years of Follow-Up in the Canadian Census Health and Environment Cohort (CanCHEC). Environ. Health Perspect. 123, 1180-1186 (2015).

2. Pope, C. A., Coleman, N., Pond, Z. A. \& Burnett, R. T. Fine particulate air pollution and human mortality: $25+$ years of cohort studies. Environ. Res. 183, 108924 (2020).

3. Brook, R. D. et al. Particulate matter air pollution and cardiovascular disease: an update to the scientific statement from the american heart association. Circulation 121, 2331-2378 (2010).

4. Wu, X., Nethery, R. C., Sabath, B. M., Braun, D. \& Dominici, F. Exposure to air pollution and COVID-19 mortality in the United States: a nationwide cross-sectional study. MedRxiv https://doi.org/10.1101/2020.04.05.20054502v2 (2020).

5. Cohen, A. J. et al. Estimates and 25-year trends of the global burden of disease attributable to ambient air pollution: an analysis of data from the Global Burden of Diseases Study 2015. The Lancet 389, 1907-1918 (2017).

6. Horne, B. D. et al. Short-term elevation of fine particulate matter air pollution and acute lower respiratory infection. Am. J. Respir. Crit. Care Med. 198, 759-766 (2018).

7. Rhee, J. et al. Impact of long-term exposures to ambient PM2.5 and ozone on ARDS risk for older adults in the United States. Chest 156, 71-79 (2019).

8. Bhaskar, A., Chandra, J., Braun, D., Cellini, J., Dominici, F. Air pollution, SARS-CoV-2 transmission, and COVID-19 outcomes: A state-of-the-science review of a rapidly evolving research area. medRxiv (2020) https://doi.org/10.1101/2020.08.16.20175901

9. Pozzer, A. et al. Regional and global contributions of air pollution to risk of death from COVID-19. Cardiovasc. Res. 116, 2247-2253 (2020).

10. Benmarhnia, T. Linkages between air pollution and the health burden from COVID-19: methodological challenges and opportunities. Am. J. Epidemiol. 189, 1238-1243 (2020).

11. Di, Q. et al. Air pollution and mortality in the medicare population. N. Engl. J. Med. 376, 2513-2522 (2017).

12. Shi, L. et al. Low-concentration PM 2.5 and mortality: estimating acute and chronic effects in a population-based study. Environ. Health Perspect. 124, 46-52 (2016).

13. Air quality management in the United States. (National Academies Press, 2004).

14. Jiang, Z. et al. Unexpected slowdown of US pollutant emission reduction in the past decade. Proc. Natl. Acad. Sci. 115, 5099-5104 (2018).

15. Zigler, C. M. \& Dominici, F. Point: clarifying policy evidence with potential-outcomes thinking-beyond exposure-response estimation in air pollution epidemiology. Am. J. Epidemiol. 180, 1133-1140 (2014).

16. Dockery, D. W. et al. Effect of air pollution control on mortality and hospital admissions in Ireland. Res. Rep. Health Eff. Inst. 3-109 (2013).

17. Chen, Y., Ebenstein, A., Greenstone, M. \& Li, H. Evidence on the impact of sustained exposure to air pollution on life expectancy from China's Huai River policy. Proc. Natl. Acad. Sci. 110, 12936-12941 (2013).

18. Henneman, L. R. F. et al. Air quality accountability: developing long-term daily time series of pollutant changes and uncertainties in Atlanta, Georgia resulting from the 1990 Clean Air Act Amendments. Environ. Int. 123, 522-534 (2019).

19. Badger, E. \& Parlapiano, A. Government Orders Alone Didn't Close the Economy. They Probably Can’t Reopen It. https://www. nytimes.com/2020/05/07/upshot/pandemic-economy-government-orders.html. (2020).

20. Dominici, F., Greenstone, M. \& Sunstein, C. R. Particulate matter matters. Science 344, 257-259 (2014).

21. Xiang, J. et al. Impacts of the COVID-19 responses on traffic-related air pollution in a Northwestern US city. Sci. Total Environ. 747, 141325 (2020).

22. Berman, J. D. \& Ebisu, K. Changes in U.S. air pollution during the COVID-19 pandemic. Sci. Total Environ. 739,139864 (2020).

23. Bekbulat, B. et al. PM25 and ozone air pollution levels have not dropped consistently across the US following societal covid response. Sci. Total Environ. https://doi.org/10.26434/chemrxiv.12275603.v6 (2020).

24. Goldberg, D. L. et al. Disentangling the impact of the COVID-19 lockdowns on urban NO2 from natural variability. Geophys. Res. Lett. https://doi.org/10.1029/2020GL089269 (2020).

25. Karaer, A., Balafkan, N., Gazzea, M., Arghandeh, R. \& Ozguven, E. E. Analyzing COVID-19 impacts on vehicle travels and daily nitrogen dioxide (NO2) levels among Florida counties. Energies 13, 6044 (2020).

26. Parker, H. A., Hasheminassab, S., Crounse, J. D., Roehl, C. M. \& Wennberg, P. O. Impacts of traffic reductions associated with COVID-19 on Southern California air quality. Geophys. Res. Lett. 47, e2020GL090164 (2020).

27. Miech, J. A., Herckes, P. \& Fraser, M. P. Effect of COVID-19 travel restrictions on phoenix air quality after accounting for boundary layer variations. ScienceDirect. (2021).

28. Gillingham, K. T., Knittel, C. R., Li, J., Ovaere, M. \& Reguant, M. The short-run and long-run effects of covid-19 on energy and the environment. Joule 4, 1337-1341 (2020).

29. Chen, L.-W.A., Chien, L.-C., Li, Y. \& Lin, G. Nonuniform impacts of COVID-19 lockdown on air quality over the United States. Sci. Total Environ. 745, 141105 (2020).

30. Sarfraz, M., Shehzad, K. \& Farid, A. Gauging the air quality of New York: a non-linear Nexus between COVID-19 and nitrogen dioxide emission. Air Qual. Atmos. Health 13, 1135-1145 (2020). 
31. Hudda, N., Simon, M. C., Patton, A. P. \& Durant, J. L. Reductions in traffic-related black carbon and ultrafine particle number concentrations in an urban neighborhood during the COVID-19 pandemic. Sci. Total Environ. 742, 140931 (2020).

32. Zangari, S., Hill, D. T., Charette, A. T. \& Mirowsky, J. E. Air quality changes in New York City during the COVID-19 pandemic. Sci. Total Environ. 742, 140496 (2020).

33. Liu, Q. et al. Spatiotemporal impacts of COVID-19 on air pollution in California, USA. Sci. Total Environ. 750, 141592 (2021).

34. Naeger, A. R. \& Murphy, K. Impact of COVID-19 containment measures on air pollution in California. Aerosol Air Qual. Res. 20, 2025-2034 (2020).

35. Fu, F., Purvis-Roberts, K. L. \& Williams, B. Impact of the COVID-19 pandemic lockdown on air pollution in 20 major cities around the world. Atmosphere 11, 1189 (2020).

36. Venter, Z. S., Aunan, K., Chowdhury, S. \& Lelieveld, J. COVID-19 lockdowns cause global air pollution declines. Proc. Natl. Acad. Sci. 117, 18984-18990 (2020).

37. Ching, J. \& Kajino, M. Rethinking air quality and climate change after COVID-19. Int. J. Environ. Res. Public. Health 17, 5167 (2020).

38. Forster, P. M. et al. Current and future global climate impacts resulting from COVID-19. Nat. Clim. Change 10, 913-919 (2020).

39. Covid-19 Changes Climate Patterns. Public Health Post https://www.publichealthpost.org/research/covid-19-changes-the-clima te-patterns/.

40. Bao, R. \& Zhang, A. Does lockdown reduce air pollution? Evidence from 44 cities in northern China. Sci. Total Environ. 731, $139052(2020)$.

41. Aloi, A. et al. Effects of the COVID-19 lockdown on urban mobility: empirical evidence from the City of Santander (Spain). Sustainability 12, 3870 (2020).

42. Tobías, A. et al. Changes in air quality during the lockdown in Barcelona (Spain) one month into the SARS-CoV-2 epidemic. Sci. Total Environ. 726, 138540 (2020).

43. Miyazaki, K. et al. Air Quality Response in China Linked to the 2019 Novel Coronavirus (COVID-19) Lockdown. Geophys. Res. Lett. 47, e2020GL089252 (2020).

44. Toro, A. R. et al. Air pollution and COVID-19 lockdown in a large South American city: Santiago Metropolitan Area. Chile. Urban Clim. 36, 100803 (2021).

45. Vadrevu, K. P. et al. Spatial and temporal variations of air pollution over 41 cities of India during the COVID-19 lockdown period. Sci. Rep. 10, 16574 (2020).

46. Viatte, C. et al. Ammonia and PM2.5 air pollution in Paris during the 2020 COVID lockdown. Atmosphere 12, 160 (2021).

47. Wang, P., Chen, K., Zhu, S., Wang, P. \& Zhang, H. Severe air pollution events not avoided by reduced anthropogenic activities during COVID-19 outbreak. Resour. Conserv. Recycl. 158, 104814 (2020).

48. Wu, C.-L. et al. Impact of the COVID-19 lockdown on roadside traffic-related air pollution in Shanghai. China. Build. Environ. https://doi.org/10.1016/j.buildenv.2021.107718 (2021).

49. Malpede, M. \& Percoco, M. Lockdown measures and air quality: evidence from Italian provinces. Lett. Spat. Resour. Sci. https:// doi.org/10.1007/s12076-021-00267-4 (2021).

50. Benchrif, A., Wheida, A., Tahri, M., Shubbar, R. M. \& Biswas, B. Air quality during three covid-19 lockdown phases: AQI, PM25 and NO2 assessment in cities with more than 1 million inhabitants. Sustain. Cities Soc. 74, 103170 (2021).

51. Hammer, M. S. et al. Effects of COVID-19 lockdowns on fine particulate matter concentrations. Sci. Adv. 7, eabg7670 (2021).

52. Outdoor Air Quality Data, https://www.epa.gov/outdoor-air-quality-data/download-daily-data.

53. AirNow, https://www.airnow.gov/.

54. Abatzoglou, J. T. Development of gridded surface meteorological data for ecological applications and modelling. Int. J. Climatol. 33, 121-131 (2013).

55. 2014 National Emissions Inventory Report. https://gispub.epa.gov/neireport/2014/.

56. Census Regions and Divisions of the United States. https://www2.census.gov/geo/pdfs/maps-data/maps/reference/us_regdiv.pdf.

57. U.S. Census Bureau (2010). Population Density Data. Retrieved from: https://www.census.gov/data/tables.html.

58. Raifman, J. et al. COVID-19 US State Policy Database. (2020) doi:10.3886/E119446V1.

59. Hyndman, R. J. \& Athanasopoulos, G. Forecasting: principles and practice. (OTexts, 2014).

60. Box, G. E. P., Jenkins, G. M., Reinsel, G. C. \& Ljung, G. M. Time series analysis: forecasting and control. (John Wiley \& Sons, Inc, 2016).

61. Bergmeir, C., Hyndman, R. J. \& Benítez, J. M. Bagging exponential smoothing methods using STL decomposition and Box-Cox transformation. Int. J. Forecast. 32, 303-312 (2016).

62. Hyndman, R. J. \& Khandakar, Y. Automatic Time Series Forecasting: The forecast Package for R. J. Stat. Softw. 27, (2008).

63. Konishi, S. \& Kitagawa, G. Information Criteria and Statistical Modeling. in 245-247.

64. Hyndman, R. J. \& Koehler, A. B. Another look at measures of forecast accuracy. Int. J. Forecast. 22, 679-688 (2006).

65. Shilling, F. \& Waetjen, D. Special Report(Update): Impact of COVID19 Mitigation on Numbers and Costs of California Traffic Crashes. 11 https://roadecology.ucdavis.edu/files/content/projects/COVID_CHIPs_Impacts.pdf.

66. Chen, K. L., Henneman, L. R. F. \& Nethery, R. C. Differential impacts of COVID-19 lockdowns on PM2.5 across the United States. medRxiv https://doi.org/10.1101/2021.03.10.21253284 (2021).

67. Brodersen, K. H., Gallusser, F., Koehler, J., Remy, N. \& Scott, S. L. Inferring causal impact using Bayesian structural time-series models. Ann. Appl. Stat. 9, 247-274 (2015).

68. Abadie, A., Diamond, A. \& Hainmueller, J. Synthetic control methods for comparative case studies: estimating the effect of California’s tobacco control program. J. Am. Stat. Assoc. 105, 493-505 (2010).

69. He, G., Pan, Y. \& Tanaka, T. The short-term impacts of COVID-19 lockdown on urban air pollution in China. Nat. Sustain. https:// doi.org/10.1038/s41893-020-0581-y (2020).

70. Wildfires and Acres | National Interagency Fire Center. https://www.nifc.gov/fire-information/statistics/wildfires.

\section{Author contributions}

T.D and P.T. led the statistical analyses and the drafting of the paper, including code and results for the supplemental material. D.B. directed its implementation, including quality assurance and control and helped with the writing of the manuscript. L.K reviewed the literature and edited the manuscript. L.H. conducted literature review and helped with the discussion. B.S. performed data acquisition from the Environmental Protection Agency and AirNow websites. F.D. directed the study implementation, the study's analytic strategy, edited the manuscript and prepared the discussion sections.

\section{Funding}

U.S. Environmental Protection Agency (83587201-0), National Institutes of Health (R01ES026217) 2020 Starr Friedman Award, Harvard University, Climate Change Solutions Fund. 


\section{Competing interests}

The authors declare no competing interests.

\section{Additional information}

Supplementary Information The online version contains supplementary material available at https://doi.org/ 10.1038/s41598-021-02776-0.

Correspondence and requests for materials should be addressed to F.D.

Reprints and permissions information is available at www.nature.com/reprints.

Publisher's note Springer Nature remains neutral with regard to jurisdictional claims in published maps and institutional affiliations.

(c) (1) Open Access This article is licensed under a Creative Commons Attribution 4.0 International License, which permits use, sharing, adaptation, distribution and reproduction in any medium or format, as long as you give appropriate credit to the original author(s) and the source, provide a link to the Creative Commons licence, and indicate if changes were made. The images or other third party material in this article are included in the article's Creative Commons licence, unless indicated otherwise in a credit line to the material. If material is not included in the article's Creative Commons licence and your intended use is not permitted by statutory regulation or exceeds the permitted use, you will need to obtain permission directly from the copyright holder. To view a copy of this licence, visit http://creativecommons.org/licenses/by/4.0/.

(C) The Author(s) 2021 